\title{
Process Optimization for Fermentation of Wine from Jackfruit (Artocarpus heterophyllus Lam.)
}

\author{
Nirmal Sharma*, Sonam Palmoo Bhutia, and Danesh Aradhya
}

Department of Food Technology, Baba Farid Institute of Education and Research, Suddhowala, Dehradun, India

\begin{abstract}
The under-utilization of Jackfruit and its post harvest losses has been a grave problem for Jackfruit cultivators. This particular fruit is not exploited fully despite the fact that it has a very good sugar content and antioxidant activity. Because of the sugar content present, Jackfruit juice is a very good substrate for fermentation. In order to prevent the post harvest loss, Jackfruit juice can be used for wine production. This work has been done to study the conditions that affect the fermentation of wine from Jackfruit. Jackfruit juice was divided into 3 parts and the $\mathrm{pH}$ was adjusted to 4,5 and 6 . The juices with the adjusted $\mathrm{pH}$ were added to different bottles and maintained at a temperature of $27^{\circ} \mathrm{C}$ $32^{\circ} \mathrm{C}$, and $37^{\circ} \mathrm{C} .9$ bottles were used for each temperature condition, which contained an inoculum concentration of $5 \%, 10 \%$, and $15 \%$ for each $\mathrm{pH}$. Samples were collected on a weekly basis and were tested for sugar content, alcohol content, polyphenol content, antioxidant activity and $\mathrm{pH}$. Jackfruit wine underwent an acidic fermentation and in most cases, fermentation completed in the $14^{\text {th }}$ day itself, with a maximum alcohol content of $18 \%$. The wine also showed a good antioxidant activity. The final product gave a sweet aroma, enhancing its sensory characteristics. Wine production from jackfruit can be a very good method for the value addition to the particular fruit.
\end{abstract}

Keywords: Jackfruit wine; Jackfruit; Process optimization; Value addition; Wine making

\section{Introduction}

India is one of the leading producers of fruits. But, most of the fruits do not reach the table of the consumers. There is a loss of around $40 \%$ per year. The reasons can be attributed to improper post harvest methods, and under utilization of fruits for value added products. Certain fruits like jackfruit, passion fruit, litchi etc. can be utilized in making wine, which not only gives a value addition, but they can also be a good source of income.

Wine can be considered as an effective nutraceutical. Studies have shown that wine consumption can provide a good health benefit like reduction of heart diseases, reducing risk of cancers, antioxidant function, reduction of depression etc [1]. Red wines can cut the risk of lung cancer [2]. Moderate drinking of wine can increase bone mass in elderly women [3]. Some people use wine to reduce anxiety, stimulate the appetite, and improve digestion by increasing stomach acids. Wine is sometimes applied directly to the skin to improve wound healing and resolve the small nodules near joints that sometimes occur with rheumatoid arthritis. Wine also contains a compound "resevatrol", which is believed to play a cardio-protective role [4]. Moderate alcohol consumption also reduces the risk of Type II diabetes. Data demonstrate that wine drinking is a general indicator of optimal social, cognitive, and personality development in Denmark [5].

It has been shown that moderate but frequent consumption of wine reduces the incidence of CHD. Alcohol raises High-density lipoproteins (HDL) subfractions which have been found to be protective against $\mathrm{CHD}$ [6]. In most countries, a high intake of saturated fat is positively related to high mortality from CHD. However, the situation in France is paradoxical. The strikingly low incidence of CHD in France, despite an intake of a high-fat diet, has been attributed to the consumption of red wine [7].

The present study documents the value addition of one such underutilized fruit - jackfruit. Jackfruit is widely grown in South India and it is also believed that the fruit evolved from the Western Ghats. In India, the fruit is not utilized properly. A large amount of this fruit goes waste. Therefore, it has become necessary that proper post harvest measures and value addition is applied to make jackfruit commercially viable. It has a very good sugar content and antioxidant activity, and less calories, which can be beneficial for health. Jackfruit pulps are usually consumed fresh as it has a low shelf life, i.e., 2-3 days, after which they will start to rot. Therefore, it is necessary to process the fruit and transform into different food products to give it an economic value (Andre et al). Jackfruit is rich in sugars and has lesser calories. It has good amount of antioxidants and it is rich in potassium. This study deals with the optimization of those conditions for wine preparation from jackfruit. Wine from jackfruit can be good for health as it has good antioxidant activity, and studies have reported that health from wine is due to the presence of antioxidants in them. Jackfruit is widely available in India, and most fruit goes waste due to its improper utilization and exploitation. In India, the fruit is sold usually by roadside vendors. Proper post harvesting and methods of value addition to this fruit can be really helpful from a nutritional and commercial perspective as well. Jackfruit can be used to prepare jams, sweetened curds, juices, dried chips and wines as well.

Since wine can be made from various fruit sources, this work is an attempt to give a value addition to the less commercially utilized jackfruit, as well as a study on its health benefits. Not much of work has been done on the utilization of jackfruit for commercial wine production. So this dissertation has been carried out to study the

*Corresponding author: Nirmal Sharma, Department of Food Technology, Baba Farid Institute of Education and Research, Suddhowala, Dehradun, India, Tel: +918348201323; E-mail: nirmalsharma1986@yahoo.com

Received September 09, 2012; Accepted December 07, 2012; Published December 15, 2012

Citation: Sharma N, Bhutia SP, Aradhya D (2013) Process Optimization for Fermentation of Wine from Jackfruit (Artocarpus heterophyllus Lam.). J Food Process Technol 4: 204. doi:10.4172/2157-7110.1000204

Copyright: (c) 2013 Sharma N, et al. This is an open-access article distributed under the terms of the Creative Commons Attribution License, which permits unrestricted use, distribution, and reproduction in any medium, provided the original author and source are credited. 
properties of jackfruit and as well as to study the various parameters that can affect the fermentation of jackfruit juice.

\section{Materials and Methods}

The main focus was kept on 3 aspects: Temperature, $\mathrm{pH}$ and Inoculum concentration. As fermentation of wine is influenced by these above factors, 3 temperature conditions $\left(27^{\circ} \mathrm{C}, 32^{\circ} \mathrm{C}\right.$ and $\left.37^{\circ} \mathrm{C}\right)$ were maintained, 3 different $\mathrm{pH}(4,5,6)$ were also maintained and the inoculum concentrations were maintained at $5 \%, 10 \%$ and $15 \%$. These factors greatly influence the yeast activity and alcohol produced.

Therefore, the reason behind choosing these conditions is to study the fermentation characteristics at different $\mathrm{pH}$, Temperature and Inoculum concentrations, as well as the optimisation of the parameters.

\section{Preparation of seed culture}

Fresh jackfruit pulps were purchased from the local market and washed thoroughly in running tap water. The seeds were removed and the seedless bulbs were graded to remove the unwanted ones. Then the pulps were cut into fine pieces. $229.5 \mathrm{~g}$ of the pulp, $558 \mathrm{ml}$ of water and $112.0 \mathrm{~g}$ of sugar was added and blended in a blender to obtain jackfruit juice. The juice was filtered and was transferred to a conical flask and autoclaved in an autoclave at $121^{\circ} \mathrm{C}$ for 15 minutes to inhibit the growth of unwanted micro-organisms. The contents of the conical flask were allowed to cool to the room temperature inside the laminar air flow chamber. The extract of juice was inoculated using $0.3 \mathrm{~g}$ yeast extract to facilitate the growth of yeast cells (S. cerevisiae). These were incubated at $30^{\circ} \mathrm{C}$ on rotary shaker $(150 \mathrm{rpm})$ overnight and the contents of the flasks were then, mixed and used as an inoculum for the fermentation.

\section{Preparation of sample/must}

$1708.5 \mathrm{~g}$ of cut pieces of seedless jackfruit pulps was taken and 4154 $\mathrm{ml}$ of water was added. 837.5 gram of jaggery was added and mixed well and blended to obtain juice. $6750 \mathrm{ml}$ of the must was obtained. $250 \mathrm{~mL}$ of the must was then added into each pre-sterilised bottles for fermentation. The $\mathrm{pH}$ of the must was adjusted to 4, 5, and 6 for each temperature and inoculum concentration. The bottles were then autoclaved again at $121^{\circ} \mathrm{C}$ for 15 minutes and inoculum was added to each bottle. Each temperature maintained contained 9 bottles per batch with $\mathrm{pH}$ of 4,5 , and 6 . Each $\mathrm{pH}$ maintained contained inoculum concentration of $5 \%, 10 \%$ and $15 \%$. These were then kept at different temperatures.

\section{Experimental setup}

During the experimental setup for the fermentation of jackfruit juice, optimization of 3 parameters was considered: temperature, $\mathrm{pH}$ and inoculum concentration. Three different temperature conditions are maintained in this experiment: $27^{\circ} \mathrm{C}, 32^{\circ} \mathrm{C}$ and $37^{\circ} \mathrm{C}$. The different $\mathrm{pH}$ conditions maintained are 4,5 and 6 . The inoculum concentrations used are $5 \%, 10 \%$ and $15 \%$. To perform the experiment, 27 bottles were taken and sterilized prior to addition of juice and inoculum.

A starter of Saccharomyces cerevisiae strain was then transferred into each jackfruit juice sample and incubated in a conical flask fitted with a rubber cork under anaerobic condition at pre-optimised temperatures. To prevent explosion by carbon dioxide produced from the fermentation, the conical flask was connected to another conical flask containing distilled water using a rubber pipe. Samples were taken out on $7^{\text {th }}, 14^{\text {th }}$ and $21^{\text {st }}$ day for the testing of following constituents. After samples were extracted every time, the growth of yeast was inhibited by keeping the samples at $60^{\circ} \mathrm{C}$ in a water bath for 30 minutes.
All the chemicals used for testing were of analytical grade and the list of chemicals and instruments are given below.

\section{Instruments}

Spectrophotometer, weighing balance and $\mathrm{pH}$ meter: BOECO, Germany

Blender: Waring Commercial, USA

Incubator: Salvis lab

Autoclave: Astell

\section{Chemicals}

$\mathrm{CuSO}_{4}$, FC Reagent, Ammonium molybdate, Ascorbic acid: MERCK, Mumbai

$\mathrm{H}_{2} \mathrm{SO}_{4}$, Tannic acid, Sodium potassium tartarate: SDFCL, Mumbai

Phenol, Sodium carbonate, $\mathrm{NaOH}$ : HiMedia Laboratories

Disodium orthophosphate: Therono Fisher Scientific, India

\section{Methods}

The $\mathrm{pH}$ of the extracted wine samples was measured and then tested for various contents.

Estimation of total sugars (Phenol-H2SO4 method): 0.2, 0.4, 0.6, 0.8 and $1 \mathrm{~mL}$ of the working standard were pipetted into a series of test tubes. $0.2 \mathrm{~mL}$ of the sample solution was pipetted into a test tube. The volume in each tube was made up to $1 \mathrm{ml}$ with distilled water. Blank was set with $1 \mathrm{ml}$ of water. Then, $1 \mathrm{ml}$ of $5 \%$ Phenol was added to each test tube. After some time, $5 \mathrm{ml}$ of concentrated Sulphuric Acid was added to all the tubes and shaken well. After ten minutes, the contents in the test tubes were shaken well and kept in water bath at $25-30^{\circ} \mathrm{C}$ for 20 minutes. The absorbance of each solution in the sample was noted using spectrophotometer at $490 \mathrm{~nm}$. Standard graph was prepared using the standards and the total sugars were calculated for each sample (Sawhney and Singh, 2006).

Estimation of polyphenols using FC method: Different aliquots of standard tannic acid solution (20-100 $\mu \mathrm{l})$ were taken in test tubes. The volume was made up to $200 \mu \mathrm{l}$ with distilled water. $0.5 \mathrm{ml}$ wine sample was taken for the estimation of polyphenols. $4 \mathrm{ml}$ of $2 \%$ Sodium Carbonate solution was added along with $200 \mu$ of Folin's phenol. The test tubes were incubated at room temperature for 30 minutes. The colour developed was read in a spectrophotometer at $760 \mathrm{~nm}$ against a reagent blank. A standard graph was plotted and the percentage of total phenolic content was calculated using the standard graph (Singleton and Rossi, 1965).

Estimation of alcohol using specific gravity method: Specific gravity bottle was cleaned thoroughly by washing it with acetone followed by washing it with distilled water and finally with alcohol. Bottle was then dried with the help of drier. The bottle was stoppered and the bottle with stopper was weighed and the weight was noted down as $\mathrm{W}_{1} \mathrm{~g}$. The bottle was filled with distilled water upto the brim and the stopper was inserted allowing the excess water to flow out. The bottle was wiped thoroughly and weighed. The weighed value was noted down as $\mathrm{W}_{2} \mathrm{~g}$. The contents of the bottle were removed and the bottle was dried with the help of drier. Bottle was filled with sample of wine, stoppered and weighed. The weight was noted down as $\mathrm{W}_{3} \mathrm{~g}$. The room temperature was noted down to obtain density of water.

Total antioxidant capacity using phosphomolybdate method: 0.3 
Citation: Sharma N, Bhutia SP, Aradhya D (2013) Process Optimization for Fermentation of Wine from Jackfruit (Artocarpus heterophyllus Lam.). J Food Process Technol 4: 204. doi:10.4172/2157-7110.1000204

Page 3 of 5

$\mathrm{mL}$ of wine sample was mixed with $3 \mathrm{~mL}$ reagent solution $(6 \mathrm{M}$ sulfuric acid, $28 \mathrm{mM}$ sodium phosphate and $4 \mathrm{mM}$ ammonium molybdate. The reaction mixture was incubated at $95^{\circ} \mathrm{C}$ for $90 \mathrm{~min}$. The mixture was cooled to room temperature and the absorbance of the solution was measured at $695 \mathrm{~nm}$ against blank. Based on the reading the percentage scavenging activity was calculated (Prieto et al. 1999).

\section{Results and Discussions}

Effect of yeast and initial sugar concentrations and time on the fermentation process was investigated. The profile of ethanol and sugar

Average Alcohol \% Produced on 7th, 14th and 21st dat

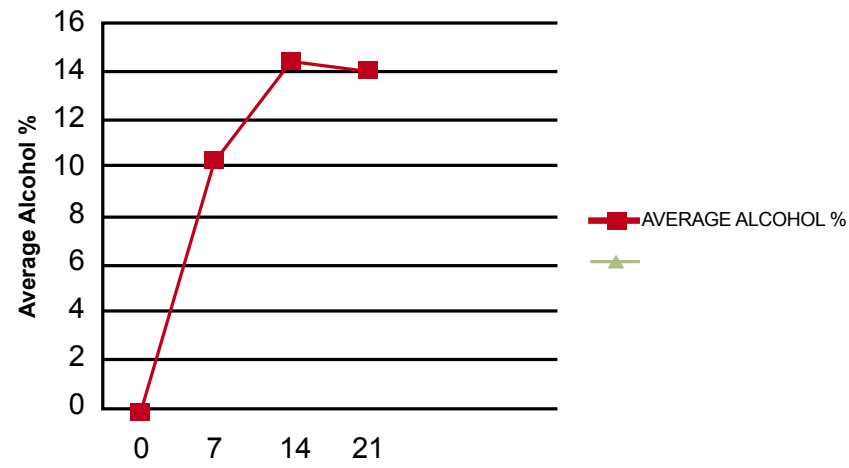

Figure 1: Average Alcohol \% Produced on $7^{\text {th }}, 14^{\text {th }}$ and $21^{\text {st }}$ day. concentrations as a function of time at various yeast concentrations, temperatures and $\mathrm{pH}$ are presented in Figure 1. The reduction in sugar concentration indicated that some sugar contained in the jackfruit juice has been consumed by yeast as a substrate to grow and converted it to ethanol. A comparative change in $\mathrm{pH}$, alcohol content in the $7^{\text {th }}, 14^{\text {th }}$ and $21^{\text {st }}$ day is shown in Table 1 and the total phenolics and antioxidant activity is shown in Table 2 . Samples were extracted on $7^{\text {th }}, 14^{\text {th }}$ and $21^{\text {st }}$ day and the inhibition of growth of yeast was done by heating the samples in a water bath at $60^{\circ} \mathrm{C}$ for 30 minutes. Tests were performed for sugars, polyphenols, alcohol content, and $\mathrm{pH}$ and antioxidant activities of the extracted samples. The sugar content decreased drastically on $7^{\text {th }}$ and $14^{\text {th }}$ day. In some of the bottles, almost $90 \%$ of sugars were fermented between $7^{\text {th }}$ and $14^{\text {th }}$ day, and alcohol content was around $11-14 \%$ on an average in the $14^{\text {th }}$ day. The fermentation process slowed down after the $14^{\text {th }}$ day. Some of the sugars were completely fermented on the $14^{\text {th }}$ day itself, whereas in some setups the remaining sugars probably got converted to organic acids. Almost a half of the sugar was been consumed by yeast in 7 days in most of the samples. This phenomenon agrees well with that reported by Wang where primary wine fermentation lasts for approximately one week; during that time most of the sugar originally presents in the juice is converted to ethanol and yeast cells, with the evolution of carbon dioxide. The average changes in various constituents (alcohol produced, sugars consumed, antioxidant activity, polyphenol content) is shown in Figure 3.

\section{Sugars}

The concentration of sugars decreased gradually, and almost all

\begin{tabular}{|c|c|c|c|c|c|c|c|c|c|c|c|}
\hline \multirow[t]{3}{*}{ Initial pH } & \multirow[t]{3}{*}{ Culture \% } & \multirow[t]{3}{*}{ Temp. ${ }^{\circ} \mathrm{C}$} & \multicolumn{3}{|c|}{ Alcohol $(\%)$ in days } & \multirow{2}{*}{\multicolumn{3}{|c|}{$\begin{array}{c}\text { Total Sugars }(\% \mathrm{~g} / \mathrm{L}) \text { in days } \\
0^{\text {th }} \text { day }-19 \%\end{array}$}} & \multicolumn{3}{|c|}{$\mathrm{pH}$} \\
\hline & & & \multirow[b]{2}{*}{$7^{\text {th }}$} & \multirow[b]{2}{*}{$14^{\text {th }}$} & \multirow[b]{2}{*}{$21^{\text {st }}$} & & & & & & \\
\hline & & & & & & $7^{\text {th }}$ & $14^{\text {th }}$ & $21^{\text {st }}$ & $7^{\text {th }}$ & $14^{\text {th }}$ & $21^{\text {st }}$ \\
\hline 4 & 5 & 27 & 7.9 & 16.1 & 16.1 & 10.35 & 1.13 & 1.05 & 3.34 & 3.35 & 3.36 \\
\hline 4 & 10 & 27 & 12.6 & 15.9 & 18.1 & 7.75 & 3.4 & 0.97 & 3.39 & 3.39 & 3.37 \\
\hline 4 & 15 & 27 & 12.7 & 15.8 & 12.6 & 7.97 & 1.35 & 1.19 & 3.54 & 3.55 & 3.51 \\
\hline 5 & 5 & 27 & 13.9 & 15.3 & 14.6 & 1.27 & 1.18 & 1.17 & 4.34 & 4.56 & 4.41 \\
\hline 5 & 10 & 27 & 12.3 & 14.3 & 13.1 & 1.5 & 1.23 & 1.19 & 3.58 & 3.61 & 3.55 \\
\hline 5 & 15 & 27 & 12.1 & 15.6 & 16.1 & 1.71 & 1.66 & 1.52 & 4.38 & 4.56 & 4.58 \\
\hline 6 & 5 & 27 & 12.2 & 15.7 & 10.5 & 5.41 & 0.98 & 0.97 & 4.58 & 4.76 & 4.57 \\
\hline 6 & 10 & 27 & 13.6 & 11.1 & 10.3 & 1.15 & 1.12 & 1.07 & 3.64 & 3.64 & 3.60 \\
\hline 6 & 15 & 27 & 13.5 & 11.7 & 15.4 & 6.3 & 4.01 & 1.71 & 4.54 & 4.76 & 4.45 \\
\hline 4 & 5 & 32 & 13.6 & 14.2 & 15.9 & 5.9 & 5.4 & 1.32 & 3.88 & 3.42 & 3.36 \\
\hline 4 & 10 & 32 & 14.6 & 16.5 & 11.1 & 6.31 & 0.78 & 0.69 & 4.17 & 4.0 & 4.11 \\
\hline 4 & 15 & 32 & 4.4 & 18.0 & 13.8 & 10.18 & 0.89 & 0.85 & 3.39 & 3.32 & 3.37 \\
\hline 5 & 5 & 32 & 10.2 & 11.8 & 14.9 & 8.26 & 4.3 & 0.78 & 3.57 & 3.59 & 3.52 \\
\hline 5 & 10 & 32 & 9.8 & 13 & 17.4 & 8.8 & 6.51 & 0.9 & 3.58 & 3.58 & 3.41 \\
\hline 5 & 15 & 32 & 13.4 & 11.1 & 13.2 & 1.35 & 1.33 & 1.09 & 3.54 & 3.51 & 3.42 \\
\hline 6 & 5 & 32 & 6.6 & 8.4 & 8.5 & 9.72 & 6.35 & 1.06 & 3.62 & 3.35 & 3.35 \\
\hline 6 & 10 & 32 & 4.3 & 11.4 & 11.2 & 10.21 & 0.8 & 0.71 & 3.60 & 3.59 & 3.60 \\
\hline 6 & 15 & 32 & 11.1 & 13.9 & 13.3 & 7.35 & 0.62 & 0.5 & 3.61 & 3.61 & 3.55 \\
\hline 4 & 5 & 37 & 14.3 & 15.5 & 13.2 & 1.35 & 1.2 & 1.18 & 3.38 & 3.43 & 3.42 \\
\hline 4 & 10 & 37 & 5.8 & 18.7 & 12.8 & 9.21 & 1.64 & 1.57 & 3.36 & 3.33 & 3.48 \\
\hline 4 & 15 & 37 & 8.9 & 14.9 & 19.3 & 7.3 & 3.21 & 0.52 & 3.40 & 3.43 & 3.52 \\
\hline 5 & 5 & 37 & 19.2 & 15.1 & 12.6 & 1.56 & 1.42 & 1.4 & 4.41 & 4.55 & 4.50 \\
\hline 5 & 10 & 37 & 14.4 & 15.5 & 14.6 & 1.74 & 1.54 & 1.52 & 3.59 & 3.51 & 3.48 \\
\hline 5 & 15 & 37 & 19.0 & 16.2 & 17.3 & 0.97 & 0.96 & 0.94 & 4.45 & 4.51 & 4.49 \\
\hline 6 & 5 & 37 & 13.1 & 16.3 & 16.3 & 1.42 & 1.33 & 1.31 & 4.56 & 4.63 & 4.71 \\
\hline 6 & 10 & 37 & 15.3 & 9.5 & 11.1 & 1.21 & 1.19 & 1.12 & 3.58 & 3.61 & 3.56 \\
\hline 6 & 15 & 37 & 13.6 & 14.2 & 15.9 & 6.35 & 3.92 & 0.89 & 4.60 & 4.64 & 4.65 \\
\hline
\end{tabular}

Table 1: Comparison of changes in various parameters during jackfruit wine fermentation-l. 
Citation: Sharma N, Bhutia SP, Aradhya D (2013) Process Optimization for Fermentation of Wine from Jackfruit (Artocarpus heterophyllus Lam.). J Food Process Technol 4: 204. doi:10.4172/2157-7110.1000204

Page 4 of 5

the sugars got fermented in the $14^{\text {th }}$ day itself in most of the cases. Within the $7^{\text {th }}$ day in most cases, the sugar concentration decreased to more than half. The total sugar content in the $14^{\text {th }}$ day in most cases was around $1-2 \%$. This implies that fermentation was rapid and sugars were getting fermented to alcohol. The cumulative percentage of sugars decreased as the fermentation progressed, is shown in Figure 2.

\section{Total phenolics and antioxidant activity}

The phenolic contents also increased, as well as the antioxidant activity. Maximum antioxidant activity seen was $36 \%$. On the $21^{\text {st }}$ day, the highest phenolic content was $7.5 \% \mathrm{mg} / \mathrm{L}$ and the lowest phenolic

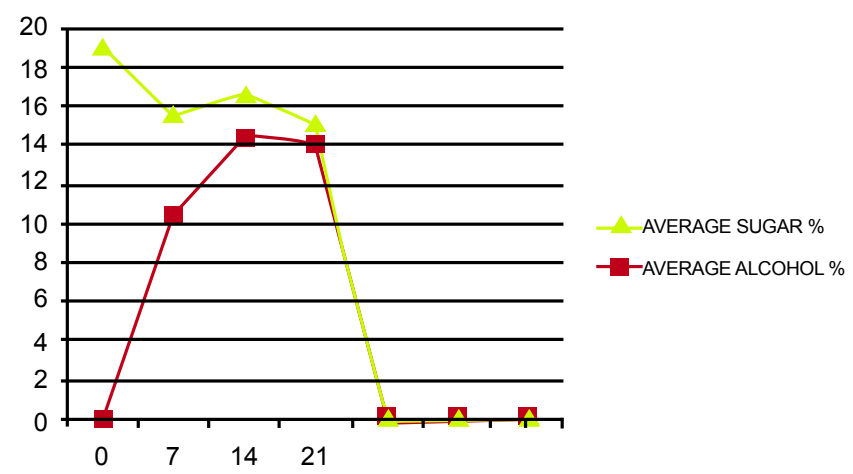

Figure 2: Average Alcohol \% vs Average Sugars Concentration on $7^{\text {th }}, 14^{\text {th }}$ and $21^{\text {st }}$ day. content was $4.3 \% \mathrm{mg} / \mathrm{L}$. The maximum antioxidant activity achieved on the $21^{\text {st }}$ day was $36 \%$ and the minimum antioxidant activity was $7.8 \%$.

\section{Alcohol content}

The highest alcohol content achieved was around 19\%. Alcohol content increased gradually during $7^{\text {th }}$ and the $14^{\text {th }}$ day. In most cases, it has been seen that fermentation stopped by the $14^{\text {th }}$ day itself, producing an alcohol content of around $11-13 \%$. On the $21^{\text {st }}$ day, the highest alcohol obtained was $19.3 \%$ and the lowest alcohol content was $8.5 \%$. The $\mathrm{pH}$ of the samples was checked immediately after extraction, and there was a significant decrease, hence acidic fermentation was taking place. This study revealed that wine production from jackfruit juice by fermentation using Saccharomyces cerevisiae can be done in less than two weeks. It has also been seen that alcohol production is affected by various parameters. The result of the various tests performed was tabulated and is given in Tables 1 and 2 . The cumulative percentage of alcohol produced on $7^{\text {th }}, 14^{\text {th }}$ and $21^{\text {st }}$ day is shown in Figure 1.

\section{Summary and Conclusion}

From the above results, it can be concluded that jackfruit can be a very important source for commercial wine production and $\mathrm{pH}$, temperature and inoculum concentration play an important role during the fermentation of jackfruit wine. It is also been seen that fermentation is faster in jackfruit, which corroborates to earlier findings by Andre et al. Jackfruit wine possesed good antioxidant activity, owing to its gradual increase in phenolic content as the fermentation progressed.

\begin{tabular}{|c|c|c|c|c|c|c|}
\hline \multirow[t]{3}{*}{ Initial pH } & \multirow[t]{3}{*}{ Culture (\%) } & \multirow[t]{3}{*}{ Temp. ${ }^{\circ} \mathrm{C}$} & \multicolumn{3}{|c|}{ Polyphenols (\% mg/L) } & \multirow{3}{*}{$\begin{array}{c}\text { Antioxidant Activity (\%) } \\
0^{\text {th }} \text { day }-11.5 \\
21^{\text {st }}\end{array}$} \\
\hline & & & \multicolumn{3}{|c|}{$0^{\text {th }}$ day -3.49} & \\
\hline & & & $7^{\text {th }}$ & $14^{\text {th }}$ & $21^{\text {st }}$ & \\
\hline 4 & 5 & 27 & 4.2 & 5.7 & 4.9 & 16.3 \\
\hline 4 & 10 & 27 & 4.2 & 4.6 & 4.6 & 26.3 \\
\hline 4 & 15 & 27 & 6.3 & 5.4 & 5.1 & 21.3 \\
\hline 5 & 5 & 27 & 4.1 & 3.5 & 4.8 & 22.0 \\
\hline 5 & 10 & 27 & 4.3 & 5.3 & 5.6 & 28.9 \\
\hline 5 & 15 & 27 & 3.7 & 3.7 & 7.5 & 24.7 \\
\hline 6 & 5 & 27 & 3.9 & 4.8 & 4.6 & 7.8 \\
\hline 6 & 10 & 27 & 4.2 & 4.2 & 6.0 & 14.9 \\
\hline 6 & 15 & 27 & 3.2 & 3.7 & 4.6 & 20.0 \\
\hline 4 & 5 & 32 & 4.2 & 5.2 & 4.9 & 20.2 \\
\hline 4 & 10 & 32 & 3.4 & 3.3 & 3.8 & 13.2 \\
\hline 4 & 15 & 32 & 4.2 & 6.0 & 4.8 & 34.0 \\
\hline 5 & 5 & 32 & 4.3 & 4.4 & 5.2 & 36.0 \\
\hline 5 & 10 & 32 & 4.2 & 5.4 & 4.3 & 18.1 \\
\hline 5 & 15 & 32 & 5.1 & 4.7 & 5.2 & 8.9 \\
\hline 6 & 5 & 32 & 4.2 & 3.9 & 4.7 & 24.4 \\
\hline 6 & 10 & 32 & 4.2 & 5.1 & 5.1 & 43.2 \\
\hline 6 & 15 & 32 & 4.3 & 5.2 & 5.1 & 18.4 \\
\hline 4 & 5 & 37 & 4.7 & 4.8 & 5.2 & 17.0 \\
\hline 4 & 10 & 37 & 4.4 & 7.4 & 5.0 & 10.7 \\
\hline 4 & 15 & 37 & 4.3 & 3.9 & 5.3 & 9.3 \\
\hline 5 & 5 & 37 & 4.7 & 6.0 & 5.6 & 22.0 \\
\hline 5 & 10 & 37 & 4.1 & 5.3 & 5.0 & 15.0 \\
\hline 5 & 15 & 37 & 5.1 & 3.5 & 5.4 & 24.0 \\
\hline 6 & 5 & 37 & 5.1 & 4.9 & 5.0 & 20.5 \\
\hline 6 & 10 & 37 & 4.4 & 5.4 & 5.5 & 11.3 \\
\hline 6 & 15 & 37 & 4.3 & 4.5 & 4.7 & 15.8 \\
\hline
\end{tabular}

Table 2: Comparison of changes in various parameters during jackfruit wine fermentation-II. 
Citation: Sharma N, Bhutia SP, Aradhya D (2013) Process Optimization for Fermentation of Wine from Jackfruit (Artocarpus heterophyllus Lam.). J Food Process Technol 4: 204. doi:10.4172/2157-7110.1000204

Page 5 of 5

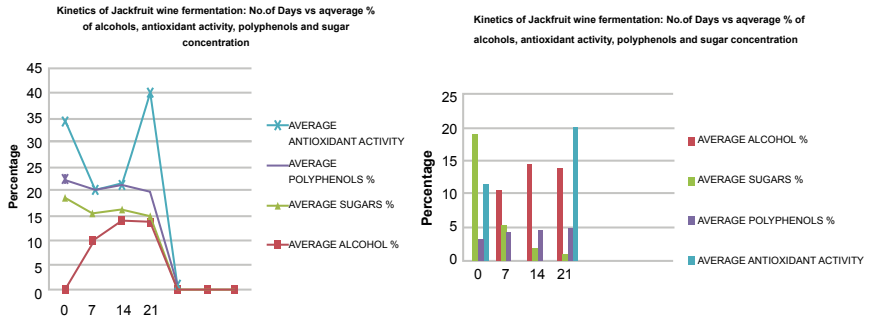

Figure 3: Kinetics of Jackfruit wine fermentation: No. of Days vs average $\%$ of alcohols, antioxidant activity, polyphenols and sugar concentration.

Jackfruit can be called a wonder fruit because of its great benefits. It has low calorie, high protein and antioxidants in seeds. The work was done by me as an attempt to provide a value addition to an underutilised fruit. Though jackfruit finds its origin in India, not much work on its value addition is done. Therefore, this work is an attempt to provide a value addition to jackfruit. The present work indicates that wines with high alcohol content can be produced from jackfruit juice, with a good number of polyphenols and antioxidant activity. The fermentation is affected by $\mathrm{pH}$, temperature and inoculum concentration and $12-14 \%$ alcohol content can be achieved in 2 weeks, which can rise up to $19 \%$ in $21^{\text {st }}$ day.
The present work concludes that utilization of jackfruit in the production of wine will be beneficial to health as well. The wine has a sweet jackfruit smell, hence, giving an added advantage to its sensory properties. Hence, this work also concludes that underutilised fruits can be used for value addition.

\section{References}

1. Bhavya HT (2009) Transformation of polyphenols in fruits during fermentation: Wine from passion fruit (Passiflora edulis). CFTRI, Mysore, India.

2. Wilbert C (2008) Moderate Drinking of Red Wine Linked to Lower Lung Cancer Risk Among Smokers. WebMD Health News.

3. Gaffney J (2000) Wine Spectator.

4. DeNoon JD (2008) In Test Tube, Red Wine Supplement Blocks Estrogen Toxicity. WebMD Health News.

5. Mortensen EL, Jensen HH, Sanders SA, Reinisch JM (2001) Better psychological functioning and higher social status may largely explain the apparent health benefits of wine: a study of wine and beer drinking in young Danish adults. Arch Intern Med 161: 1844-1848.

6. Kannel WB, Ellison RC (1996) Alcohol and coronary heart disease: the evidence for a protetive effect. Clin Chim Acta 246: 59-76.

7. Kumoro AC, Rianasari D, Pinandita APP, Retnowati DS, Budiyati CS (2012) Preparation of Wine from Jackfruit (Artocarpus heterophyllus lam) Juice Using Baker yeast: Effect of Yeast and Initial Sugar Concentrations. World Applied Sciences Journal 16: 1262-1268. 